\title{
Rapid growth of zinc oxide nanobars in presence of electric field by physical vapor deposition
}

\author{
Mehraban Jouya $^{1} \cdot$ Fahime Taromian $^{1} \cdot \operatorname{Simin}$ Siami $^{1}$
}

Received: 3 May 2017 / Accepted: 25 November 2017 / Published online: 3 January 2018

(C) The Author(s) 2018. This article is an open access publication

\begin{abstract}
In this contribution, electric field has some effects to increase growth for specific time duration on zinc oxide $(\mathrm{ZnO})$ nanobars. First, the zinc $(\mathrm{Zn})$ thin film has been prepared by $235,000 \mathrm{~V} / \mathrm{m}$ electric field assisted physical vapor deposition (PVD) at vacuum of $1.33 \times 10^{-5}$ mbar. Second, strong electric field of $134,000 \mathrm{~V} / \mathrm{m}$ has been used in ambient for growing $\mathrm{ZnO}$ nanobars in term of the time include 2.5 and $10 \mathrm{~h}$. The performances of the $\mathrm{ZnO}$ nanostructure in absence and presence of electric field have been determined by scanning electron microscopy (SEM) and X-ray diffraction (XRD). The results of XRD analysis showed that $\mathrm{ZnO}$ has a hexagonal bars structure and a strongly preferred (101) orientation which is strongest than without applying electric field. SEM analysis revealed that physical vapored $\mathrm{ZnO}$ thin film in presence of electric field are densely packed with uniform morphological, thinner and denser in distribution. Electric field effect for $\mathrm{ZnO}$ growth in $2.5 \mathrm{~h}$ is better than it in the $2.5 \mathrm{~h}$ without electric field but by passing the time the media influence has good power almost as same as electric field. Through this electric field in PVD, the compact and uniform $\mathrm{Zn}$ film has been achieved which is less diameter than ordinary PVD method. Finally, we carry out a series of experiments to grow differentorientation $\mathrm{ZnO}$ nanobars with less than $100 \mathrm{~nm}$ in diameter, which are the time saving process in base of PVD ever reported. Therefore, the significant conclusion in usage electric field is reducing time of growth.
\end{abstract}

Keywords $\mathrm{Zn}$ thin film $\cdot$ Physical vapor deposition (PVD) $\cdot \mathrm{ZnO}$ nanostructure $\cdot$ Strong electric field

\section{Introduction and theoretical frame work}

$\mathrm{ZnO}$ is a II-VI semiconductor compound that has been studied due to its wide range of applications in nanosystems. Most of this group semiconductors crystallize in either cubic zinc blende or hexagonal wurtzite structure where each anion is surrounded by four cations at the corners of a tetrahedron, and vice versa [1].The morphology of nanostructures is determined by the combination of kinetic effects, the growth rates of different surfaces, thermodynamic effects and the energetic stability of the overall nanostructure $[2,3]$.

Metal-oxide thin films can be deposited using a variety available growth techniques for $\mathrm{ZnO}$ which are practically

Fahime Taromian

ftaromian@mail.kntu.ac.ir

1 Department of Solid State Physics, Faculty of Physics, K. N Toosi University of Technology, POB 15875-4416, Tehran, Iran endless, including physical vapor deposition, thermal evaporation, sputtering and so on. Recently, one-dimensional oxide semiconductor materials have received great attention because of their potential applications [3, 4].

In one research was used the thermal oxidation method to synthesized $\mathrm{Fe}_{2} \mathrm{O}_{3}$ nanowires via resistive heating and a transverse electric field which was applied perpendicularly to the substrate during thermal oxidation, prepare copper oxide nanowires and applied transverse electric field to the substrates [5]. Numerous groups have modeled deposition processes of thin films [6], but here we looked specifically at $\mathrm{ZnO}$ and investigated, at the nanoscale level, the effect of strong electric field on $\mathrm{Zn}$ condensation on substrate and using normal electric field on the growth of $\mathrm{ZnO}$ in two different time ( 2.5 and $10 \mathrm{~h}$ ) of experiment. Ultimately we focused on the difference between growth produced by electric field and without it. 


\section{Methods}

Actually, the growth process of our $\mathrm{ZnO}$ nanostructure was likely to be divided into two sections. Zn granul had deposited on the lam which had been placed at the bottom of Substrate holder to produce only $\mathrm{Zn}$ nona sheet, in another hand producing $\mathrm{ZnO}$ nano structure refer to the next step (put the lam in the special temperature in ambient and apply different electric field). In both section, voltage of $4.7 \mathrm{kV}$ was used which was terminated to electric field of $235,000 \mathrm{~V} / \mathrm{m}$ in first experiment and $134,000 \mathrm{~V} / \mathrm{m}$ in second experiment. In the first experiment, the PVD method was applied in absence and presence of electric field, similarly to that described in the schematic is shown in Fig. 1 consisted of the boat, the mesh, the sample holder and indicating the voltage is applied to boat's Source.

In the PVD system, the pressure was about $1.33 \times 10^{-5} \mathrm{mbar}$, the temperature of the source was approximately equal to the $\mathrm{Zn}$ sublimation temperature. This machine comprised of RZ2 rotary pump and HP40B2 diffusion model. The source material was $\mathrm{Zn}$ granul with 99.99\% purity (merck) was placed in the molybdenum boat onto deposition chamber in the weight of $0.45 \mathrm{~g}$ and diameter of $7 \mathrm{~mm}$. The substrates were soda-lime glass plates cleaned using acetone and ultrasonically diluted with ethanol and then rinsed in deionized water and then loading into a vacuum chamber in top of the bell jar.

Initially, $\mathrm{Zn}$ metallic films deposited onto glass substrates by thermal evaporation in vacuum, followed by repeat experiment assisted by electric field. Electric field was applied between the aluminum sheet and the mesh. The as-obtained products collected, which were prepared without electric field, were labeled as Sample 1 in first experiment, and products collected under electric field were labeled as Sample 2 in first experiment.

\section{Deposition}

In the first section of experiment, the $\mathrm{Zn}$ atoms on the source were subsequently moved on the substrates which were deposited for time of $20 \mathrm{~min}$.

Parameters for coating deposition were listed in Table 1. Note that the crystallinity of the fabricated nanostructures was dependent on some parameters such as substrate distance from the $\mathrm{Zn}$ source [7], The specimen holder was connected to positive electrode of the power supply and electrically isolated from the environment.

This experiment repeated by applying normal electric field of $235,000 \mathrm{~V} / \mathrm{m}$ on $\mathrm{Zn}$ particles. To supply strong electric field, a polyamide stand was used to hold a substrate holder made of aluminum sheet as positive (anode) and aluminum mesh as negative (cathode) electrodes, respectively, inside the bell jar of the vacuum coating system. The detail of experiment was provided in the schematic diagram of Fig. 2.

After the preparation of the $\mathrm{Zn}$ thin films in absence and presence of electric field, only the samples which were in the presence of electric field were oxidated.

\section{Growth}

In the second section of experiment, film samples which were in presence of electric field were annealed at a high temperature of $550{ }^{\circ} \mathrm{C}$ in ambient, out of the PVD system, and $\mathrm{Zn}$ film could react with oxygen to form a thin oxide layer during the heat without applying electric field. Nanobars grew on a substrate which was connected to
Fig. 1 Schematic showing the PVD system

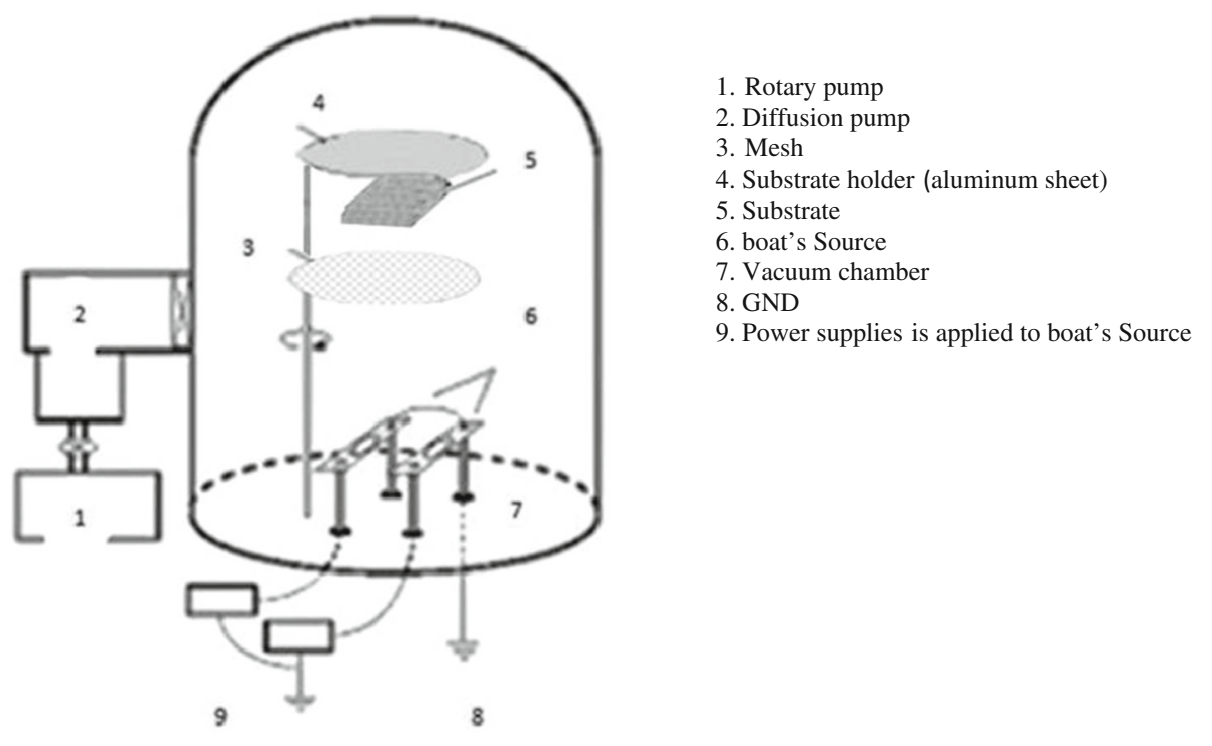


Table 1 The distribution of condition for first experiment

\begin{tabular}{llllll}
\hline $\begin{array}{l}\text { Distance between two electrode } \\
\text { (aluminum sheet and mesh) }(\mathrm{cm})\end{array}$ & $\begin{array}{l}\text { Distance between substrate and } \\
\text { evaporation source }(\mathrm{cm})\end{array}$ & $\begin{array}{l}\text { Applied } \\
V(\mathrm{kv})\end{array}$ & $\begin{array}{l}\text { Basket and } \\
\text { substrate }(\mathrm{cm})\end{array}$ & $\begin{array}{l}\text { Basket and } \\
\text { mesh }(\mathrm{cm})\end{array}$ & $\begin{array}{l}\text { Calculated } \\
E(\mathrm{v} / \mathrm{m})\end{array}$ \\
\hline 2 & 4.5 & 4.7 & 3.5 & $\begin{array}{l}\text { Time for } \\
\text { deposition } \\
(\mathrm{min})\end{array}$ \\
\hline
\end{tabular}

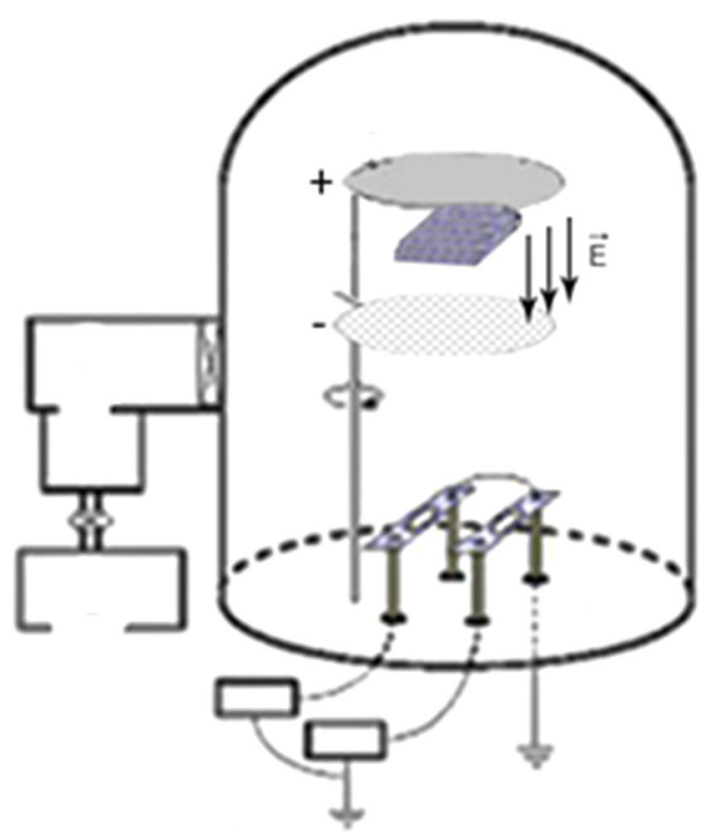

Fig. 2 Schematic showing the PVD system with applying electric field

heater consists nickel-chromium wire. Hitter connected to AC power supply. This treatment of the $\mathrm{ZnO}$ nanobars thin films occurred in 2.5 and $10 \mathrm{~h}$.

This experiment repeated by applying uniform electric field of $134,000 \mathrm{~V} / \mathrm{m}$. Positive and negative poles of aluminum plates connected to DC power supply, also we could change orientation and intensity of the electric field by changing the poles and applied different potential, so deduced the fast growth of the nanobars which is shown in SEM images Fig. 4. The condition for second experiment mentioned in Table 2. This treatment of the $\mathrm{ZnO}$ nanobars thin films occurred in 2.5 and $10 \mathrm{~h}$ too. The $\mathrm{ZnO}$ nanobars in the second experiment, which were prepared without electric field, were labeled as Sample 1 in second experiment, and products under electric field were labeled as Sample 2 in second experiment.

\section{Results and discussion}

SEM

\section{Deposition}

Referring to Fig. 3a, b in Sample 1 of first experiment, the given $\mathrm{Zn}$ granul was decomposed into smaller particles that migrate to the substrate. When this particle reached the substrate, it lacked surface energy to be deposited firmly and had a different orientation with no ordering. In Sample 2 of first experiment, when the surface energy was activated from an external source (strong electric field), it gave the system a rapid reorganization and coarsening, which permitted the different formation of the direction and diameter of the nanostructured thin films in presence of electric field of $235,000 \mathrm{~V} / \mathrm{m}$ which could be the cause of the increasing densely of the thin films in comparison with Sample 1 (Fig. 3c, d).

In a growth mechanism, the condensation created on a substrate by attachment of the vaporized atoms and by atom's migration from a source and the nuclei growth was closely dependent on the change in Gibbs free energy. Electric field in PVD method decreased the diameter of particle which was also deduced from formula in the absence of electric field (1) and in presence of electric field (2) [8]. In Sample 1 of first experiment, the average size of $\mathrm{Zn}$ particles was $683 \mathrm{~nm}$ in diameter which was more than Sample 2. In Sample 2 of first experiment, the $\mathrm{Zn}$ particles had a good arrangement and packed to each other. The average size of this sample was $617 \mathrm{~nm}$.

$$
\begin{aligned}
& \Delta G=4 / 3 \pi r^{3} \Delta G_{\mathrm{V}}+4 \pi r^{3} \gamma_{\mathrm{vf}}, \\
& d \Delta G / d r=0 \\
& r^{*}=-2 \gamma_{\mathrm{vf}} / \Delta G_{\mathrm{v}},
\end{aligned}
$$

where $\Delta G$ change of Gibbs free energy for $\mathrm{Zn}, \Delta G_{\mathrm{v}}$ change of Gibbs free energy when vapor transform into

Table 2 The distribution of condition for second experiment

\begin{tabular}{llll}
\hline Dimension of AL plates $(\mathrm{cm})$ & Distance between two plates $(\mathrm{cm})$ & Applied $V(\mathrm{kV})$ & Calculated $E(\mathrm{~V} / \mathrm{m})$ \\
\hline $20 \times 7$ & 3.5 & 4.7 & 134,000 \\
\hline
\end{tabular}


Fig. 3 First experiment: $\mathrm{Zn}$ deposition in PVD method. a scheme of Sample 1 without applying electric field. b Sample 1 without applying electric field. c scheme of Sample 2 with electric field. d Sample 2 with electric field
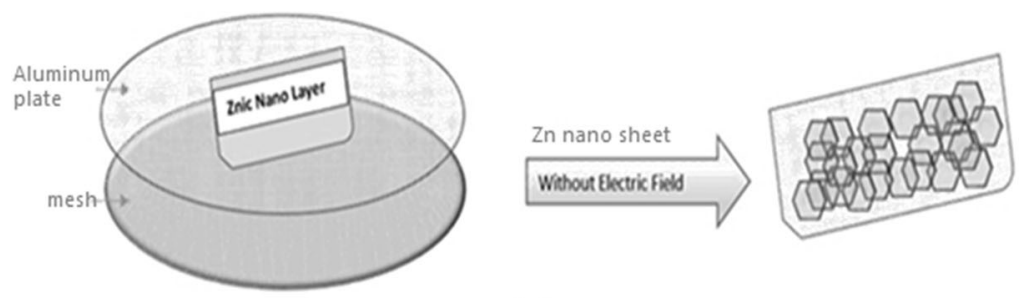

(a)

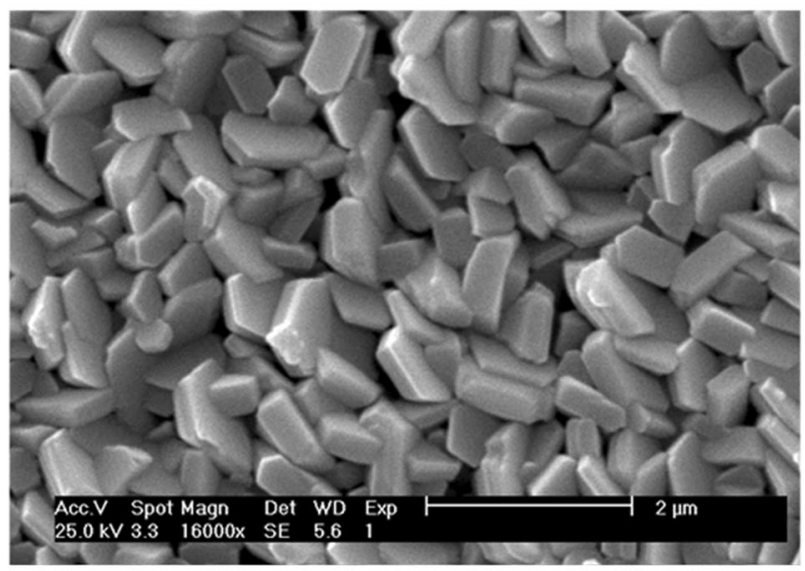

(b)

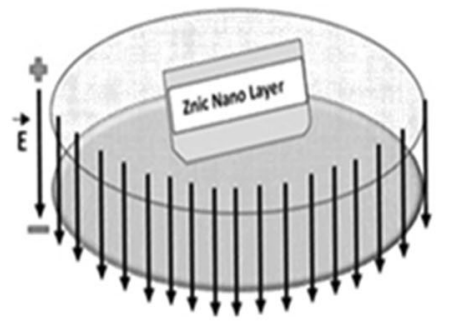
Woth Electric fived

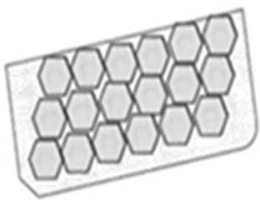

(c)

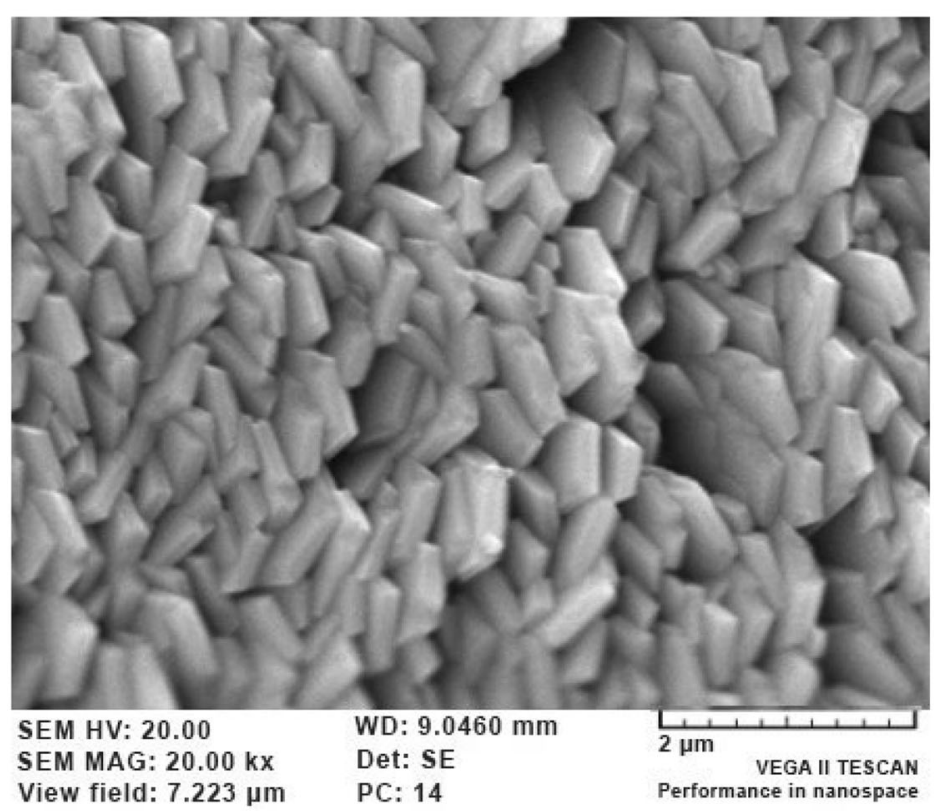

(d) 
solid, $r$ radius of created embryo, $r^{*}$ critical radius, $\gamma_{\mathrm{vf}}$ surface energy between solid and vapor.

From the (1), an initial nucleus, so called an embryo, would be appeared when the $r$ is larger than $r^{*}$, where $\Delta G$ becomes negative and then the embryo grows into the nuclei with decreasing the surface energy. Otherwise, the embryo would be re-evaporated into vacuum or migrated to the neighbor nuclei to reduce the surface energy. As shown in formula in (2), $r^{*}$ decreased when electric field had significant value in comparison with $\Delta G$,

$r^{*}=2 \sigma V_{2} /\left(\Delta G-\beta E^{2}\right)$.

So according to the first experiment condensation on substrate at the initial stage had an important role in inplane alignment of the nanobars [9]. The temperature of the substrate and the pressure were the parameters having primary influence on the coating structure [10]. SEM images revealed that the as-deposited gray-black $\mathrm{Zn}$ precursors consisted of a large quantity of $\mathrm{Zn}$ (Fig. 3d) exhibited very densely packed particles with smooth surface morphology.

\section{Growth}

The mobility of an atom on a surface will depend on the energy of the atom, atom-surface interactions (chemical bonding), and the temperature of the surface. The mobility on a surface can vary due to changes in chemistry or crystallography. The different crystallographic planes of a surface had different surface free energies which affect the surface diffusion [11].

Figure $4 \mathrm{c}-\mathrm{f}$ shows typical SEM micrographs of $\mathrm{ZnO}$ thin films deposited in ambient with and without applying electric field in different time of 2.5 and $10 \mathrm{~h}$. From Fig. 4c, namely Sample 1, we can see that there were two kinds of nanostructures, one was nanobars with several hundred nanometers in length and several tens in width, the other was large quantity of agglomerations in time of $2.5 \mathrm{~h}$ in diameter. In another hand by passing time to $10 \mathrm{~h}$ uniform nanobars were seen (Fig. 4d).

Figure $4 \mathrm{e}$, f presented the general morphology of quasione-dimensional nanostructures prepared under electric field in 2.5 and $10 \mathrm{~h}$, respectively, namely Sample 2. A mass of $\mathrm{ZnO}$ nanobars with significant different growth length were clearly observed in Fig. 4e, among them, a few group of $\mathrm{ZnO}$ nanobares were also found which were denser than another area. No agglomerations were observed on films deposited on the surface of glass whereas slight agglomerations were visible on Sample 1 without using electric field in 2.5 h. From Fig. 4f, we can clearly see there were highly homogenous and uniform $\mathrm{ZnO}$ nanobars which were free from pin holes, cracks or voids. These surface properties had strong effect on the optical properties such as transmittance, absorbance and reflection. Finally the average length of these nanobars was measured (only hint in this letter) about $320 \mathrm{~nm}$ for Sample 1 without electric field in $10 \mathrm{~h}$ and $448 \mathrm{~nm}$ for Sample 2 with electric field in $10 \mathrm{~h}$, which are shown in Fig. $4 \mathrm{a}, \mathrm{b}$ as a schematic and SEM images can be seen in Fig. 4d, f. Electric field effect on the oxidation rate indicated that oxygen ions were the predominant species diffusing in the growing oxide film and excludes oxygen atoms and oxygen molecules and process occurred when the potential of the oxide was equivalent to the change in free energy of the oxidation reaction.

A $\mathrm{Zn}$ atom on the surface is often bound by a $\mathrm{O}$ or $\mathrm{O}$ dimer to form a $\mathrm{ZnO}$ or $\mathrm{ZnO}$ cluster, both of which are illustrated here (Fig. 5) [12].

Table 3: showed the growth of $\mathrm{ZnO}$ nanowires with average diameters in the range of less than $100 \mathrm{~nm}$ (Fig. 4). The observed variation in the shape and diameter of the fabricated nanowires could be due to the presence of electric field. Note that a main goal was decrease in preparation time of nanostructures.

\section{X-ray}

XRD studies of $\mathrm{ZnO}$ thin films have been carried out using D8-Advance X-ray diffractometer made in Bruker AXS company. Surface morphology of the films is studied using field emission scanning electron microscope (VEGA2, Tescan).

Figure $4 \mathrm{~g}$, h shows the XRD patterns of Sample 1 and 2 of second experiment in $10 \mathrm{~h}$. The diffraction peaks at about $31.4(\theta), 34.08(\theta), 35.90(\theta)$ were ascribable to the (1010), (0002) and (1011) planes, respectively, in good agreement with JCPDS card no. 79-0208, $(a=2.207 \mathrm{~nm}$ and $c=3.379 \mathrm{~nm}$ ) with no trace of other phases. Note that the c/a ratio for the prepared samples was 1.53 , which is very close to the standard ratio reported for pure $\mathrm{ZnO}$ in the literature [7].

The XRD suggested that both of the films were crystalline with a hexagonal structure, In the preparation of $\mathrm{ZnO}$ nanobars, the $\mathrm{ZnO}$ phase may grow in three characteristic diffraction peaks in the initial stage; however, further growth only occurred in the [101] crystallographic direction, as this direction is energetically most favorable and involves easier diffusion and favorable stacking. It was obvious that the (101) plane is the preferred orientation in the both samples, as the peak intensity in Sample 2 of second experiment was much higher (about twice) than that of the other peaks. What's more, after applying electric field (101) plane diffraction peak intensity of this film was obviously higher than that of the film without applying electric field, because the crystallinity of the film had been 
(a)


(b)

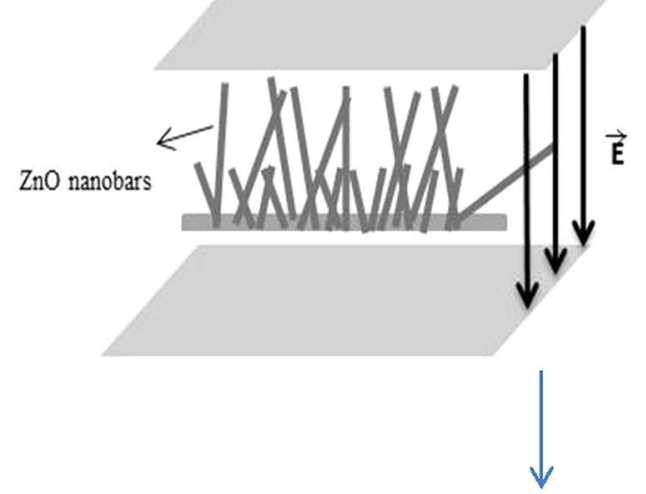

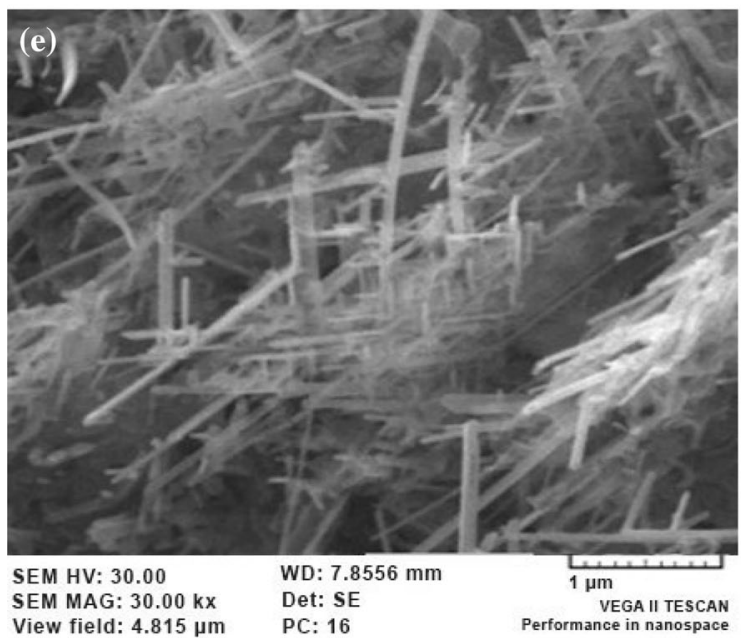

View field: $4.815 \mu \mathrm{m}$


Fig. 4 Schematic of $\mathrm{ZnO}$ growth in Second experiment, a Sample 2 without applying electric field in $10 \mathrm{~h}$, b Sample 2 with applying electric field in $10 \mathrm{~h}$. SEM pictures, c Sample 1 without applying electric field in $2.5 \mathrm{~h}$, d Sample 2 without applying electric field in

improved through this process [13], and the weakness of the peaks was related to the thickness of the thin films [14]. As atoms had relatively high activity which promoted the diffusion of atoms and resulted in preferred orientation
$10 \mathrm{~h}$, e Sample 1 with electric field in $2.5 \mathrm{~h}$, f Sample 2 with electric field in $10 \mathrm{~h}$. XRD patterns, g Sample 2 without electric field of second experiment in $10 \mathrm{~h}$, h Sample 2 with electric field

along given lattice planes. The intensity different of the (002) diffraction between samples, indicating Sample 2 had a better oriented growth along only the (101) and c-axis orientation condoned in comparison to Sample 1 [15]. 
Fig. 4 continued
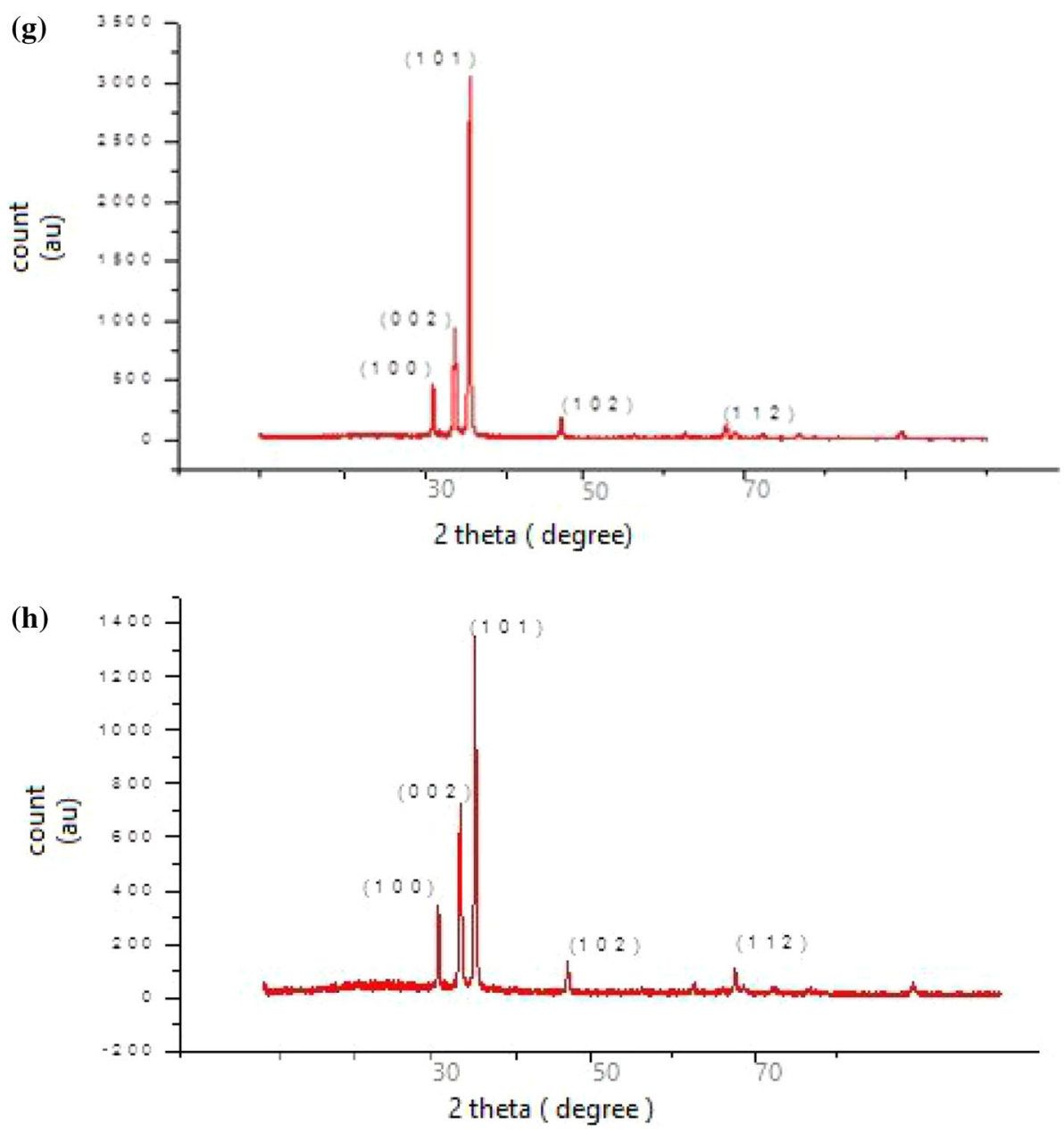

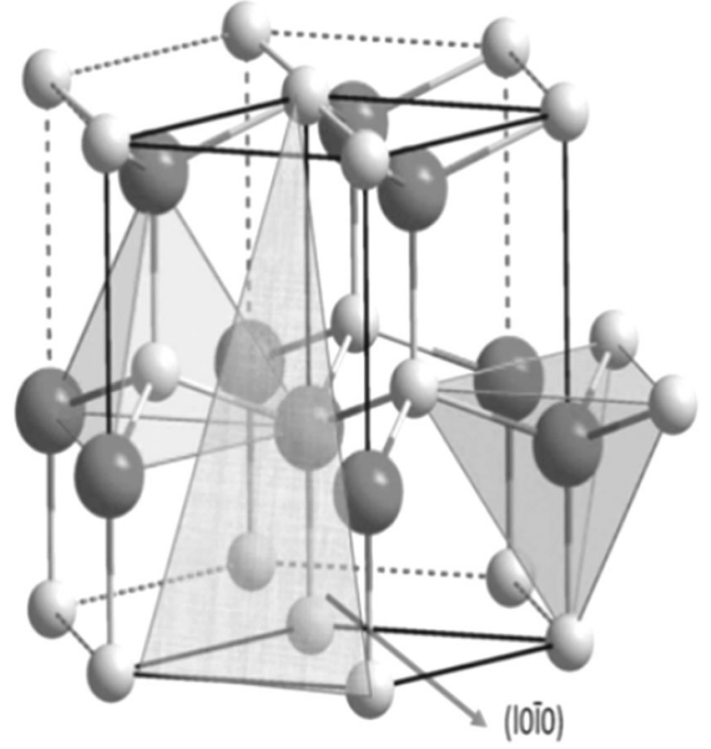

Fig. 5 (1011), growth orientation in $\mathrm{ZnO}$ structure in this experiment, white spheres represent $\mathrm{O}$, whilst larger, black spheres represent $\mathrm{Zn}$
Table 3 The distribution of condition for second experiment

\begin{tabular}{lll}
\hline Time (hours) & 2.5 & 10 \\
D in first experiment (nm) & $77 / 71$ & $60 / 58$ \\
D in second experiment (nm) & $68 / 78$ & $46 / 43$ \\
\hline
\end{tabular}

It is well accepted that phase transformations, including deposition and crystal growth were governed by thermodynamics and kinetics of the process. Studying the thermodynamics of the problem, one can judge whether a particular transformation can take place or not. Kinetics deals with the speed with which the transformation occurs. According to thermodynamics, the phase having minimum free energy would be the stable one out of the different possibilities [16]. In case, when the electric field is small and the Gibbs energy is of a significant value, the influence of the electric field at the crystal growth is negligible [17], (see Sect. 3.1.1). As illustrated in pervious sections electric field was in order of Gibbs energy. Structurally, growth orientation has some deviation from c-axis as it is shown in 
Fig. 5. As it is shown in (3), surface energy related to Gibbs free energy, these dependencies have been stated explicitly surface energy related to applying electric field [see (2)] in experiment too,

$\gamma=d G^{2} / d A$.

\section{Conclusion}

Compared with the other methods of preparation $[1,3]$, the current approach is much faster and more convenient. This finding further confirm rapid growth due to the use of electric field based-up deposition for growth mechanism to explain PVD in preparing metal oxide nanobars.

The result of the first experiment is that condensation and nucleation at the Sample 2 has a crucial role in in-plane alignment of the nanobars. Orientation of the nanobars has not massive effect in second experiment even in the presence of electric field but the fast growth is occurred due to electric field in second experiment. The overview morphology of the as-prepared products is observed by SEM. The $\mathrm{Zn}$ particles in presence of electric field had a good arrangement and packed to each other with average size of $617 \mathrm{~nm}$ which is decreased in compare to Sample 1 $(683 \mathrm{~nm})$.

The result of the second experiment is that highly [101]oriented $\mathrm{ZnO}$ nanobars were grown on $\mathrm{Zn} /$ glass substrates via simple PVD process using electric field in ambiance at temperature of $550{ }^{\circ} \mathrm{C}$. The crystal structures of the products are investigated by XRD. This result is very different from most of the $\mathrm{ZnO}$ nanostructures synthesized using other methods, in which $\mathrm{ZnO}$ often grow along the [0001] direction. The nanobars are characterized in detail in terms of their structural properties. The detailed structural investigations reveal that the as-synthesized $\mathrm{ZnO}$ nanobars are well-crystalline, possessing a perfect hexagonal ideal growth habits of wurtzite $\mathrm{ZnO}$ and grow along the [101] direction in preference.

Due to Sect. 3.2 despite strong electric field on sample, the orientation has not any noticeable change but by applying it, the crystallography is more better and the other orientation was ignored in comparison to [101]. However, as it was shown in Fig. 4, electric field apply their effect on growth in the second experiment for Sample 2 during the time of $2.5 \mathrm{~h}$ and their effect approximately stops for $10 \mathrm{~h}$ as the Sample 1 of the second experiment in $10 \mathrm{~h}$ without applying electric field had some resemblance to Sample 2 at time of $10 \mathrm{~h}$.

Finally, $\mathrm{ZnO}$ nanobars with a width of $40-80 \mathrm{~nm}$, an average length of 300-500 $\mathrm{nm}$ and an aspect ratio of 4-9 are successfully grown and aligned on a [101] direction by applying an electric field perpendicular to the surface of a thin film during its heat treatment at $550{ }^{\circ} \mathrm{C}$. This study discloses a facile approach to access preferred (1011) plane with the assistance of external-field effect in PVD method.

\section{Limitation and suggestion}

Many strategies can be used to alter conditions in experiment, such as changing the growth time, adjusting initial, and including additives with the experiment. As a result of these modifications, it has become possible to control the structural, optical, and electrical properties of $\mathrm{ZnO}$ for use in a range of advanced device applications such as solar cells as we hinted that this method is good for Schottky contacts or surgical instruments. Recent studies on $\mathrm{ZnO}$ compounds raise new questions which will undoubtedly be scrutinized in the near future.

Acknowledgements The authors would like to thank the Research Council of Khaje Nasir University of Technology for supporting this work. Partial financial support from the Iranian Nanotechnology Initiative is also acknowledged.

Open Access This article is distributed under the terms of the Creative Commons Attribution 4.0 International License (http://crea tivecommons.org/licenses/by/4.0/), which permits unrestricted use, distribution, and reproduction in any medium, provided you give appropriate credit to the original author(s) and the source, provide a link to the Creative Commons license, and indicate if changes were made.

\section{References}

1. Morkoc, H., Umit, O.: Zinc Oxide: Fundamentals, Materials and Device Technology, p 488. Wiley, Germany (2009)

2. Wilson, H.F., Tang, C., Barnard, A.S.: Morphology of zinc oxide nanoparticles and nanowires: role of surface and edge. J. Phys. Chem. 120, 9498-9505 (2016)

3. Thomas, M.A., Cui, J.: Electrodeposition of $\mathrm{ZnO}$ Nanostructures: Growth, Doping, and Physical Properties Handbook of Nanoelectrochemistry, pp 647-79. Springer, Schweiz (2015)

4. Reddy, N.K., Ahsanulhaq, Q., Kim, J.H., Hahn, Y.B.: Wellaligned $\mathrm{ZnO}$ nanorods for device applications: synthesis and characterisation of $\mathrm{ZnO}$ nanorods and $\mathrm{n}-\mathrm{ZnO} / \mathrm{p}-\mathrm{Si}$ heterojunction diodes. EPL 81, 38001 (2008)

5. Zhao, C., Xue, Y., Jiny, Y.: Effect of electric field on $\mathrm{Fe}_{2} \mathrm{O}_{3}$ nanowire growth during thermal oxidation. Mod. Phys. Lett. B 30, 1650054 (2016)

6. Islam, M.S., Hossain, M.F., Razzak, S.M.A., Haque, M.M., Saha, D.K.: Effect of deposition time on nanostructure $\mathrm{ZnO}$ thin films synthesized by Modified thermal evaporation technique. J. Nanosci. Nanotechnol. 16, 9190-9194 (2016)

7. Hassan, N.K., Hashim, M.R., Mahdi, M.A., Allam, N.K.: A catalyst-free growth of $\mathrm{ZnO}$ nanowires on $\mathrm{Si}$ (100) substrates: effect of substrate position on morphological, structural and optical properties. ECS J. Solid State Sci. Technol. 1(2), 86-89 (2012) 
8. Koh, S.K., Lee, J.H., Lee, C., Koh, K.: Nano-scale particle formation by dynamic mixing method in physical vapor deposition. Key Eng. Mater. 708, 14-19 (2016)

9. Wang, Z.L.: Zinc oxide nanostructures: growth, properties and Applications. J. Phys.: Condens. Matter 16, 829-858 (2004)

10. Islam, M.S., Hossain, M.F., Razzak, S.M.A., Haque, M.M., Saha, D.K.: Effect of deposition time on nanostructure $\mathrm{ZnO}$ thin films synthesized by Modified thermal evaporation technique. J. Nanosci. Nanotechnol. 16, 9190-9194 (2016)

11. Mattox, D.M.: Handbook of physical vapor deposition (PVD) processing film formation, adhesion, surface preparation and contamination, p. 197. William Andrew, New Jersey (1998)

12. Blackwell, S., Smith, R., Kenny, S.D., Walls, J.M., SanzNavarro, C.F.: Modelling the growth of $\mathrm{ZnO}$ thin films by PVD methods and the effects of post-annealing. J. Phys. Condens. Matter 25, 135002 (2013)

13. Luo, R., Liu, B., Yang, X., Bao, Z., Li, B., Zhang, J., Li, W., Lili, W., Feng, L.: The large-area CdTe thin film for CdS/CdTe solar cell prepared by physical vapor deposition in medium pressure. Appl. Surf. Sci. 360, 744-748 (2016)
14. Kashani, H.: The effect of parallel electric fields on the orientation of polycrystalline zinc oxide thin films produced by reactive evaporation and oxidation of zinc. J. Mater. Sci.: Mater. Electron. 7, 85-90 (1996)

15. Li, F., Li, Z., Jin, F.: Fabrication and characterization of $\mathrm{ZnO}$ micro and nanostructures prepared by thermal evaporation. Phys. B 403, 664-669 (2008)

16. Ellmer, K., Klein, A., Rech, B.: Transparent Conductive Zinc Oxide: Basics and Applications in Thin Film Solar Cells, p. 437. Springer, Berlin (2008)

17. Yurov, V.M., Guchenko, S.A., Gyngazova, M.S.: Effect of an electric field on nucleation and growth of crystals. IOP Conf. Ser. Mater. Sci. Eng. 110, 012019 (2016)

\section{Publisher's Note}

Springer Nature remains neutral with regard to177 jurisdictional claims in published maps and institutional affiliations. 